\title{
THE NEMASTOMATIDAE AND TROGULIDAE OF THE UNITED STATES.-I.
}

BY NATHAN BANKS, SEA CLIFF, N. Y.

These two families are readily separated from the other family (Phalangidae) of the Phalangida Plagiostethi by the absence of a claw to the end of the palpus. The last joint of the palpus is shorter than the preceding one; this character is also found in the male of one genus of Phalangidae (Protolophus) but not to such a marked degree. The Nemastomatidae are separated from the Trogulidae by having the coxae free, while in the latter family the coxae are united. The size of the palpus also serves to distinguish them; in the Trogulidae the palpi are very short and concealed by the projection of the eyetubercle, in the Nemastomatidae the palpi are very long and prominent, usually longer than the body.

I consider the Trogulidae the highest family of Phalangida. In the groups of arachnids below the Phalangida it is normal to have two claws to the tarsi. With the Phalangida Mecostethi (Cosmetidae, Gonglyptidae, etc.) the two hind pairs of tarsi bear two claws, the anterior pairs have but one; the palpi have a claw or curved spine at end. In the Phalangida Plagiostethi all the tarsi have but one claw, thus showing an advance. The Phalangidae still retain the palpal claw, but the Nemastomatidae and Trogulidae have lost it. The Trogulidae show their superiority to the Nemastomatidae in their more compact form, and more complicated structure. A few Nemastomatidae have been described from the United States by Packard and Simon.*

\section{TROGULIDAE.}

The Trogulidae have not previously been recorded from the United States. Two forms are known to me which appear to belong to two genera, both new. They have more tarsal joints than is common in the European forms, in this resembling more the genus Dicranolasma ; the eye-tubercle is modified on a quite different plan from that of the European forms. The two genera may be separated as follows:-

Eye tubercle projecting in the form of a spoon, two spines at each side on the anterior margin.

Ortholasma.

Eye tubercle tree-shaped, a single club at each side on the anterior margin.

Dendrolasma.

\section{Ortholasma gen. nov.}

Cephalothorax with a pair of spines at each side on the anterior margin, the eye tubercle projecting in front in the form of an

* Packard-On a new cave-fauna in Utah-Bull.

Hayden's U. S. Geol. and Geog. Survey, 1877.

Packard-New cave Arachnida.-Am. Nat. 1884.

Packard-Cave memoir-Nat. Acad. Sci. 1887 (?).

Simon-Descriptions d'Opiliones nouveaux-C. R. Soc. Ent. Belg. 1879 . 
almost flat, gradually widening plate, the tip rounded, with a more dense central rib and some side ribs connected by a membrane. Body short, one half longer than wide. Eyes but partially seen from above. Tarsi with five to seven joints. The palpi not half so long as the width of body. The sternum is united to the venter.

Ortholasma rugosa, n. sp. Length, 3.6 mm.; width, $3 \mathrm{~mm}$.; femur II, $3 \mathrm{~mm}$. ;femur I, I.6 mm. Color black, young specimens brownish, the projection of the eye tubercle brown; legs pale toward the tips. The entire. dorsal shield is roughened by the presence of ridges, somewhat regularly but complexly arranged; where the ridges inter. sect they form tubercles, which in young specimens are furnished with short clubs or spines; the arrangement of the ridges is more easily seen in young than in adult specimens. The posterior margin of the dorsal shield is furnished with a row of spines, those near the middle being the largest. The portion of the abdomen below the end of the dorsal shield is furnished with rows of tubercles. The venter and coxae have numerous rounded tubercles or large granules, more prominent in young specimens; the spiracles are more distinct in young than old specimens. The trochanters are roughened with tubercles, the other joints of the legs smoother and with short hairs; second pair of legs longest, fourth next; tibia II almost as long as femur II. Palpi furnished with short hairs, fifth joint about one-half as long as the fourth.

Southern California.

\section{Dendrolasma gen. nov.}

Cephalothorax with a club at each side on the anterior margin. Eye tubercle projecting forward in the form of a central support, with lateral branches somewhat connected at the tips, the whole forming an oval figure. Eyes distinct from above. In this as well as Ortholasma the eyes are situated at the base of the tubercle, and not carried forward on the projection as in some European forms. The form of the body is like Ortholasma; the sternum is united to the venter; leg II is proportionately longer than in Ortholasma and there are eight or ten joints in the tarsus II; tarsus I has but four joints.

Dendrolasma mirabilis n. sp. Length, 3 mm.; width, 2.I mm.; femur II, $3 \mathrm{~mm}$.; femur I, I.5 mm. Color brown or black, venter paler; projection of eye tubercle and the club at each side whitish, legs paler toward the tips. Suture between cephalothorax and abdomen and one at base of abdomen distinct. Sides and hind margin of cephalothorax with a row of tubercles more or less connected. A square just behind the eye tubercle of similar tubercles. The dorsum of the abdomen has many series of these tubercles, regularly but very complexly arranged. There are five pairs of larger tubercles on the dorsum, each bearing small clubs or spines; the anterior pairs are closer together than the posterior pairs. The hind margin of the dorsal shield is furnished with a series of clubs having lateral projections, those each side of the middle being the largest. The segments of the abdomen below the end of the dorsal shield are somewhat roughened with tubercles. The ventral segments and coxae have many rounded granules. The second joint of the mandibles has a projection above. The trochanters are very rough; the tips of the anterior coxae have partial circles of connected tubercles; on the second coxae one of these tubercles is greatly enlarged and swollen at the tip; and on the fourth there is a straight row of similar tubercles along the outer side. The legs are quite long, the second longest, and the fourth next; they are but little roughened and with short hairs. In one specimen one of the clubs on the anterior margin is cleft at the tip. The peculiar tubercles on the body are quite similar to those found in Nemastoma modesta.

Washington State (Trevor Kincaid). 

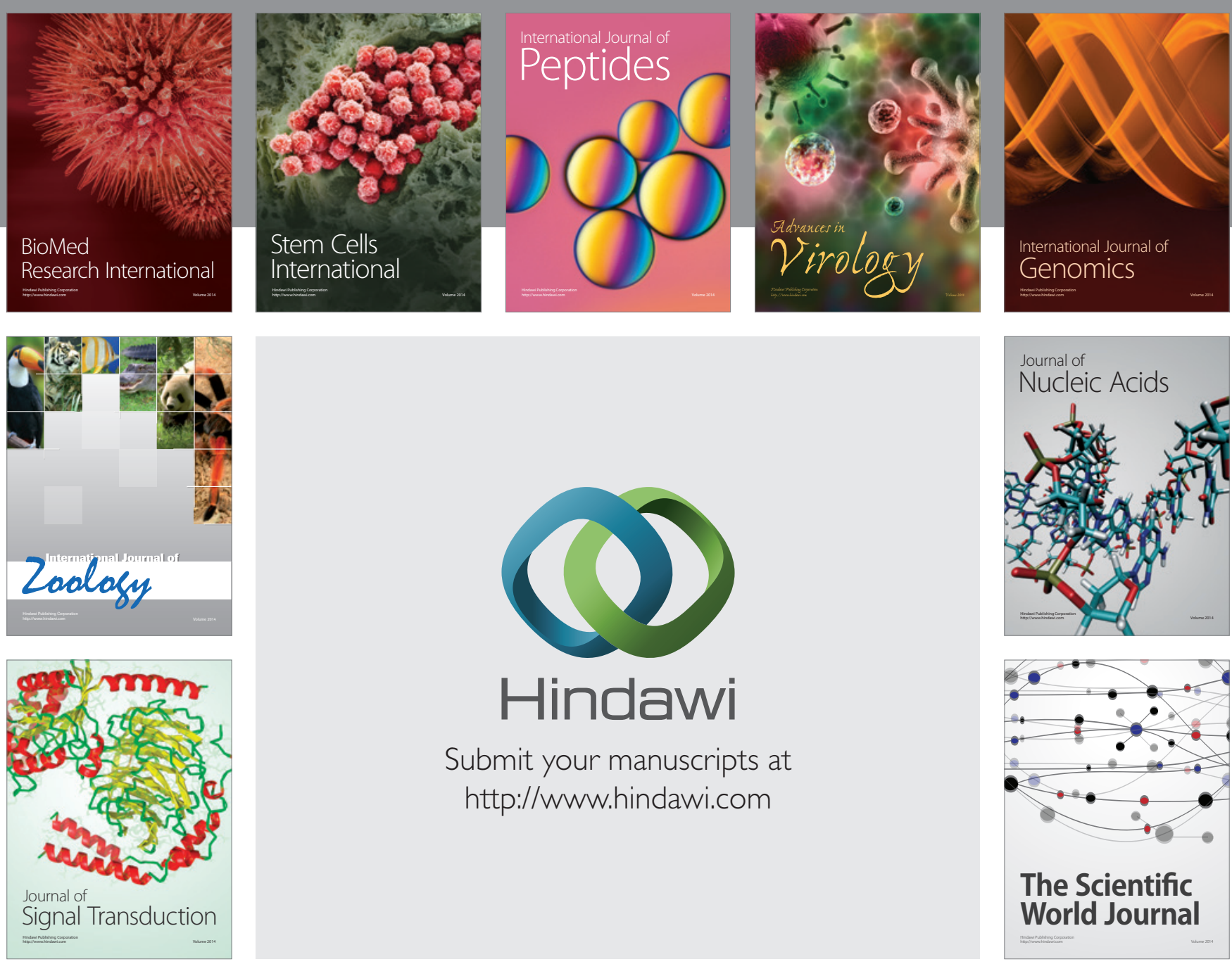

Submit your manuscripts at

http://www.hindawi.com
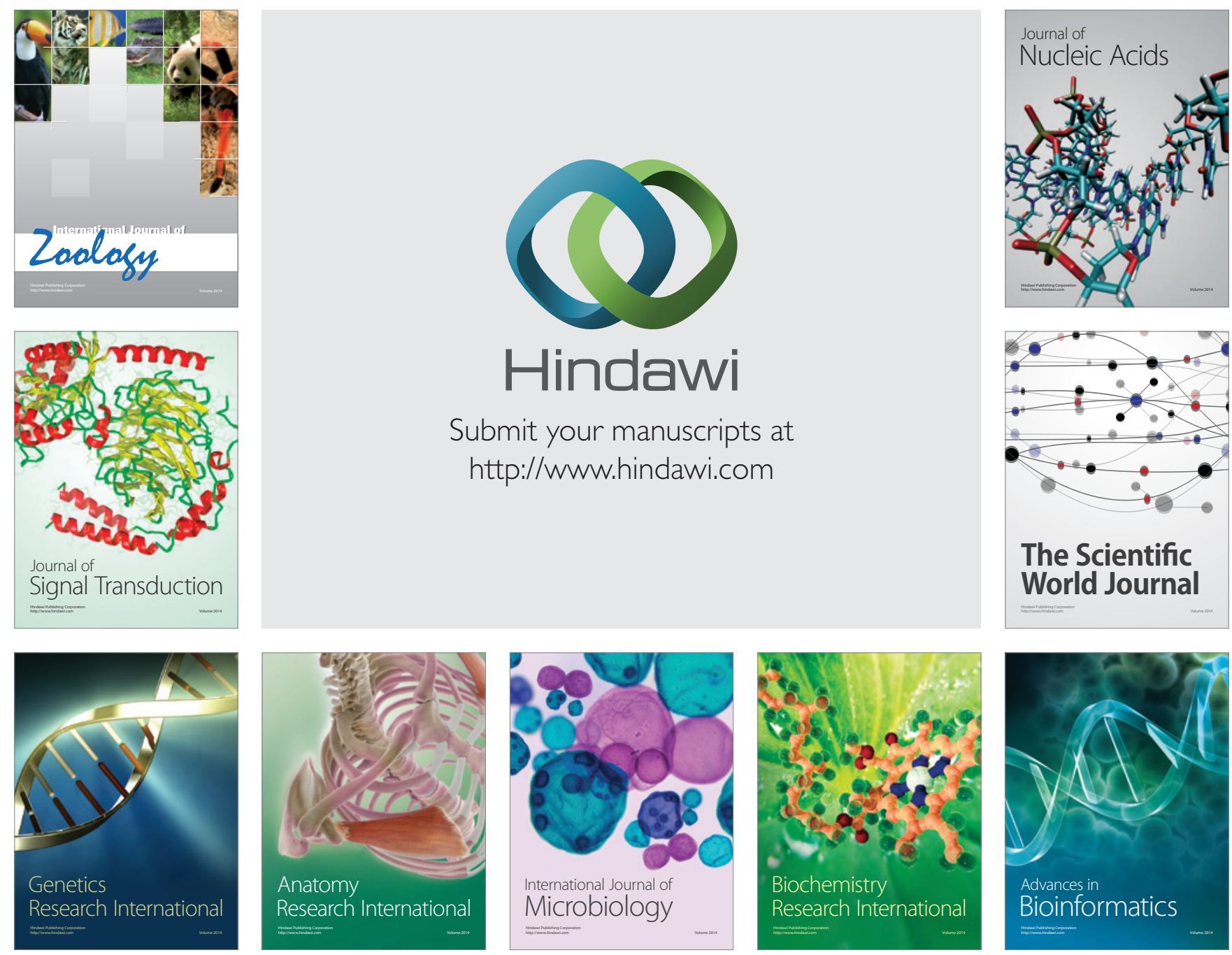

The Scientific World Journal
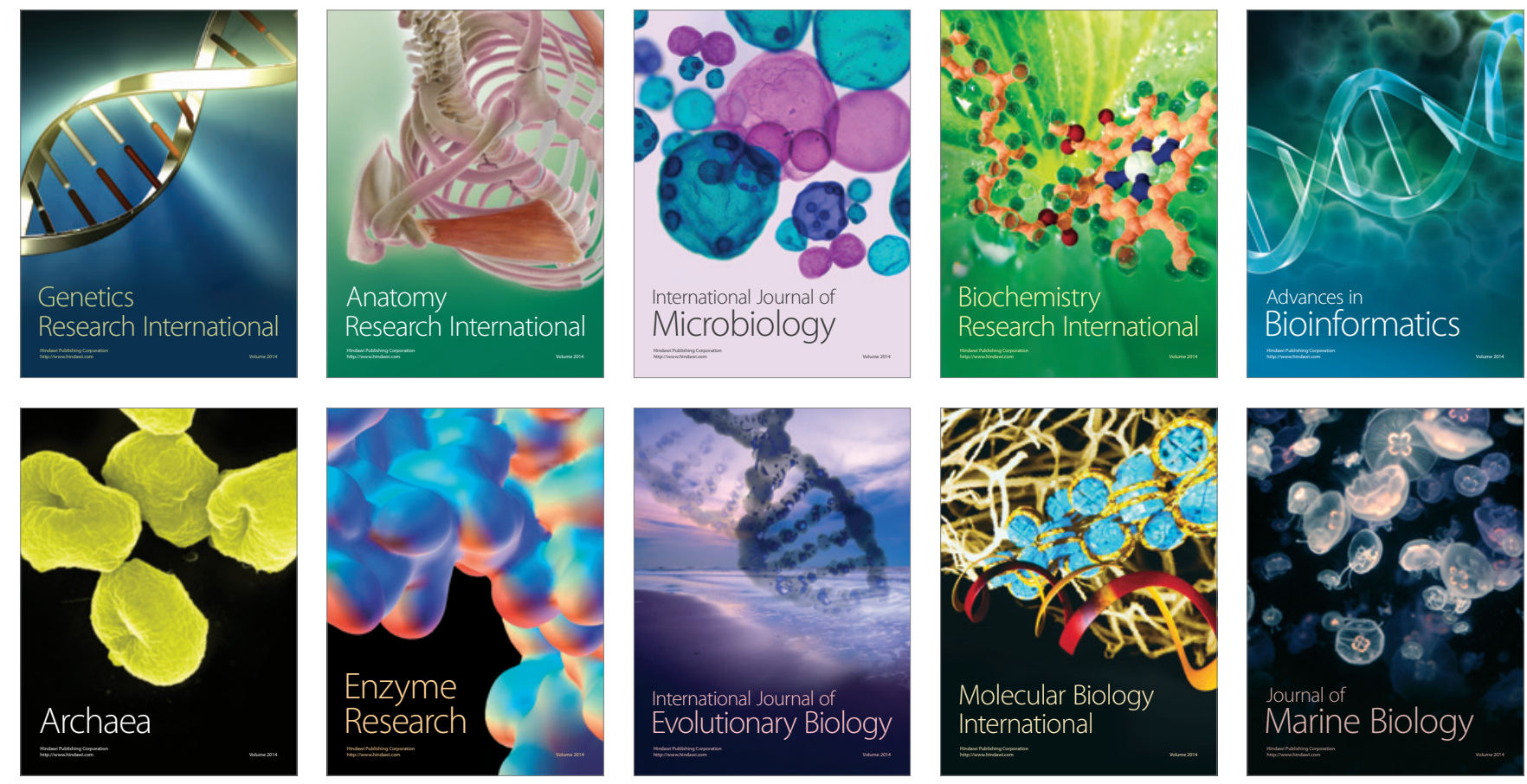